\title{
СОВРЕМЕННОЕ СОСТОЯНИЕ ВОЗДЕЙСТВИЯ СОЦИАЛЬНО-ЭКОНОМИЧЕСКИХ И ПОЛИТИКО-ПРАВОВЫХ ФАКТОРОВ НА КОРРУПЦИОННУЮ ПРЕСТУПНОСТЬ В РОССИЙСКОЙ ФЕДЕРАЦИИ
}

\begin{abstract}
Аннотация: В данной статье автором исследуется актуальная и сложная проблема, связанная с современным состоянием основных причин способствующих развитию коррупции в России. Также автор высказывает свой взгляд на данную проблему и проводит анализ наиболее важных на его взляд причин, выступающих барьером для развития антикоррупционной политики государства. В статье рассматривается место Российской Федерации на международной арене в числе стран «Большой двадцатки», в области деятельности направленной на противодействие проявления коррупционных рисков. Важнейшим методологическим направлением исследования выступает структурно-функииональный анализ, позволяющий рассмотреть различньле объектьл социальной системы с точки зрения выполняемых ими функичий по отношению к более широкому понятию коррупиия. В этой взаимосвязи были использованы элементы системного и методы сравнительного анализа, связанные с нормативно-иенностным подходом. Проведенное исследование показало, что, несмотря на то, что основные причины, способствующие возникновению и росту коррупционной составляющей в нашей стране, находятся в области экономики, их нельзя и не нужно рассматривать в отрыве от остальных, поскольку все они находятся в непосредственной взаимосвязи между собой.
\end{abstract}

Abstract: In this article the author studies a topical and complicated issue regarding the main causes of corruption development in Russia. The author also expresses his opinion and provides analysis of the most important causes, which become barriers in the way of development of the anti-corruption policy of the state. The article evaluates position of the Russian Federation in the international arena and among the "Big Twenty" states in the sphere of activities against corruption risks. The methodology of studies is based upon structural and functional analysis, allowing to evaluate various objects within the social system from the standpoint of their functions in regard to the broader interpretation of corruption. The study has shown that in spite of the fact that key causes of appearance and growth of corruption in Russia are economic, they should not be viewed outside the scope of other factors, since they are all directly related.

Ключевые слова: коррупция, коррупичонность, современное состояние, понятие, причины и условия, средства и методы, маситабы коррупици, взаимосвязь, анализ, противодействие

Keywords: corruption, corruption-related, modern condition, definition, causes and conditions, means and methods, spread of corruption, interrelation, analysis, fighting.

оррупция - одно из самых распространенных негативных явлений современной России, как правило, проявляющаяся при взаимодействии органов государственной власти с членами общества.

Масштабы коррупции таковы, что Россия признана одной из самых коррумпированных стран мира. Такой вывод делает центр Transparency International', основы-

\footnotetext{
1 Transparency International - неправительственная международная организация по борьбе с коррупцией и исследованию уровня коррупции по всему миру. Была основана в 1993 г. бывшим директором Всемирного бан-
}

ваясь на ежегодном исследовании индекса восприятия коррупции (далее - ИВК) в 180 странах мира. Центр Transparency International ежегодно измеряет ИВК в государственном секторе той или иной страны по шкале от 0 до 10 баллов, где ноль обозначает самый высокий уровень восприятия коррупции, а десять - наименьший. В 2009 году ИВК России составлял 2,2 и мы занимали 146 позицию. Кардинальных изменений за период 2010-2012 года не произошло. Россия ухудшила свои

ка Петером Айгеном в Берлине. На настоящий момент у организации существуют филиалы по всему миру. 
DOI: $10.7256 / 1811-9018.2013 .12 .10278$

При цитировании этой статьи сноска на dоі обязательна

\section{Право и политика 12 (167) • 2013}

показатели по уровню коррупции. В 2010-2012 годах России было выставлено 2,1 балла из возможных десяти, и она занимает 146 место в рейтинге ${ }^{2}$. Причем ни одна из стран входящих в G20, кроме России, не попала в низший раздел рейтинга. Таким образом, по состоянию на 2012 год Россия в рейтинге делит свое 154 место с такими странами, как Папуа - Новая Гвинея, Таджикистан, Конго и Гвинея-Бисау. Из стран СНГ в списке 2012 года лидируют Казахстан и Молдавия, занимающие 105-е место. Обогнали Россию в списке также Армения (123-е место), Белоруссия (127-е место), Украина и Азербайджан (делят 134-е место). Наивысший балл в рейтинге Transparency International получили Дания, Новая Зеландия и Сингапур - 9,3 балла. Последнее место в рейтинге заняла Сомали. Ей было присвоено 1,1 балла.

Следует заметить, что еще в 2008 году в своем докладе Д.А. Медведев ${ }^{3}$ охарактеризовал коррупцию в России, как явление системного характера, отметил, что коррупцией пронизаны все ветви и уровни власти. А раз так, то становится очевидным, что «власть» сама с собой бороться не будет.

Несмотря на громогласные заявления руководства страны, что виновные будут наказаны, лозунг «своих не сдают» в верховных кругах действует очень жестко, фигуры министерского уровня остаются практически неприкосновенными.

Как любое негативное явление, оно порождает определенные методы и способы, направленные на борьбу с ним. Но для того, что бы выработанные средства противодействия коррупции действовали максимально эффективно необходимо знать те причины и условия, которые способствуют его развитию.

За тот период, что существует коррупция, анализу и исследованию ее отдельных элементов, способов и видов ее проявления посвящено довольно значительное количество научных исследований, написано огромное количество статьей, выпущены монографии, книги, защищена не одна кандидатская и докторские диссертации.

Вместе с тем, изучению причин коррупции сопутствует ряд серьезных трудностей, во главе которых на первом месте стоит очень высокий уровень латентно-

\footnotetext{
${ }^{2}$ Интернет-интервью с руководителем аппарата Комитета Государственной Думы по безопасности и противодействию коррупции Соловьевым И.Н. «О современном состоянии антикоррупционного законодательства» (29 января 2013 г.) // СПС «Гарант». Версия от 28.07.2013 г. ${ }^{3}$ См. Послание Президента РФ Д.А. Медведева Федеральному Собранию РФ от 5 ноября 2008 г. // Российская газета. 2008. № 23.
}

сти. Более того, оценка степени коррумпированности общества значительно затруднена в связи с крайней ограниченностью показателей, которые могут быть использованы для их характеристики.

Помимо этого коррупция определяется не отдельными факторами, а является следствием сложного комплекса причин, выделить и оценить которые по отдельности представляется довольно затруднительным.

В свою очередь сами причины, обуславливающие коррупцию, по своей природе разнообразны как по формам проявлений, так и по направленности воздействия.

Именно поэтому, изучение причин и условий, способствующих возникновению и распространению коррупции, было, есть и будет актуальным до тех пор, пока ее уровень не снизится настолько, что можно говорить о «победе» над коррупцией.

Свой анализ, начнем, с того, что определим коррупцию как, устойчивое моральное разложение сознания должностных лиц системы органов государственной власти, связанное с использование своего служебного положения с целью извлечения финансовой выгоды, создающую угрозу государственной безопасности.

Существование возможности позволяющей решить «свои вопросы», связанные с необходимостью обращения к должностным лицам органов государственной власти в обход и с нарушением установленных государством норм и правил, подрывает не только государственные устои, что приводит к деформации общества и его расслоению, но и, безусловно, создает угрозу всей системе национальной безопасности, которая призвана обеспечить защиту личности.

В научной литературе неоднократно отмечалось, что истоки, корни коррупции в России следует искать в ее древней и средневековой истории. Корыстные злоупотребления по службе возникли с появлением управляющих (вождей, князей) и судей. Мздоимство упоминается в русских летописях XIII в. Одни из первых законодательных ограничений коррупционных действий были отмечены при Иване III. Иван Грозный ввел смертную казнь в качестве наказания за чрезмерность во взятках. Во время царствования Ивана Грозного произошла первая казнь за взятку - казнили дьяка, принявшего помимо положенного ему еще и начиненного монетами жареного гуся ${ }^{4}$.

Предполагается, что коррупции может быть подвержен любой кто, обладает властью над распреде-

\footnotetext{
${ }^{4}$ Гостева С.P. Противодействие коррупции - важнейшее условие укрепления национальной безопасности России.// Юридический мир. 2011. № 1.
} 
DOI: $10.7256 / 1811-9018.2013 .12 .10278$

При цитировании этой статьи сноска на dоі обязательна

Закон и правопорядок

лением каких-либо не принадлежащих ему ресурсов, возможность создавать нормы (принимать решения) порождающие определенные правовые последствия, контроль над доступом к информации ограниченной в обороте, т.е. все то, к чему имеет доступ ограниченный круг лиц (чиновники, судьи, работники правоохранительных органов, врачи, работники сферы образования и т.д.) и желает использовать ее в своих личных интересах с целью наживы.

Причины, способствующие возникновению коррупции можно разделить на несколько групп: экономические, социальные, политические и правовые.

1. Экономические.

Данная группа причин, влияющих на возникновение коррупции и ее использование, как одного из самых эффективных инструментов в руках преступных сообществ, пожалуй, самая распространенная.

Известно, что первооснову возникновения и развития коррупции составляют именно экономические отношения и экономика в целом, а основу коррупции составляют экономические правонарушения и преступления, приводящие к появлению сверх прибыли, используемой для коррупции, в том числе в виде так называемого «отката», что формирует криминальнокоррупционные сектора экономики 5 .

Наиболее важной в данной группе причин следует считать уровень заработной платы чиновника, а также периодические задержки в их выплате. Без сомнения, данный фактор, напрямую влияет на возможность проявления коррупционных наклонностей у должностного лица и приискании дополнительных источников дохода, как правило эти источники напрямую связаны с осуществлением профессиональной деятельности и отсутствием возможности (в виду полной занятости) дополнительного законного заработка. В свою очередь начавшееся «моральное разложение» конкретного чиновника и повышения его по карьерной лестнице лишь усиливают уже имеющиеся коррупционные тенденции. Поскольку, более высокая должность повышает и «аппетит» (не последнюю роль здесь играет и боязнь потерять должность) в результате чего увеличивается только размер взятки. Наряду с этим, высокие должности сами по себе порождают отдельный вид коррупции, связанный с продажей этих должностей, что само по себе не может не вызвать опасения, когда на руководящую

\footnotetext{
5 Эти идеи и соответствующие им аргументы наработаны в научной школе Академии экономической безопасности МВД России, возглавляемой заслуженным деятелем наук РФ д.э.н., профессором А.Е. Городецким.
}

должность назначается не заслуживший ее человек, а тот у кого «кошелек толще» и как следствие все вопросы связанные с выполнением своих непосредственных должностных обязанностей, он скорее всего будет решать аналогично, т.е. при помощи коррупционных схем.

В свою очередь проводимые криминологические исследования, посвященные анализу коррупционной пораженности должностных лиц в зависимости от уровня занимаемой должности, показывают, что наиболее уязвимыми с коррупционной точки зрения являются именно руководящие должности высокого уровня.

Так же к числу экономических причин можно отнести: финансовую нестабильность в обществе, общий экономический уровень развития в стране, наличие дефицитных товаров и т.П., т.е. все то, что напрямую связано с экономическим благосостоянием населения и возможностью увеличения его у отдельного индивида путем совершения противоправных коррупционных действий.

\section{2. Социальные.}

Безусловно, к основным социальным причинам данной группы следует в первую очередь отнести общую нравственную и моральную деградацию общества, отсутствие, либо крайне низкий уровень нравственного состояния населения по вопросам, затрагивающим коррупцию и ее влияние на общество и индивида, иначе говоря, правовой нигилизм.

Правовой нигилизм можно охарактеризовать как сформировавшееся в сознание устойчивое негативное отношение к праву, наличие у должностных лиц и членов общества утверждения, что достижение каких либо результатов не правовыми средствами либо с целью получения финансовой выгоды является нормой.

Существующее в настоящее время в обществе нормы морали, общий нравственный фон, полагают, что неумение «решить вопрос» и преподнести подарок (вознаграждение), даже мелкий, так что бы его у тебя взяли и посодействовали в разрешении сложившейся ситуации свидетельствует о неустроенности, неудачливости.

Определенные отпечаток на общее мнение и развитие морально-нравственной гражданской позиции по данному вопросу в значительной степени принадлежит СМИ. Как часто за последнее время мы слышали о том, что кого то из коррупционеров, не мелкого чиновника на местном уровне, а именно «Коррупционера», ворующего и присваивающего миллиарды государственных денег, наказали, причем наказали достаточно серьезно, так что бы остальным стало не повадно?

Таким образом, к числу социальных причин обуславливающих возникновение данного явления, следует отнести: крайне низкий уровень нравствен- 
DOI: $10.7256 / 1811-9018.2013 .12 .10278$

При цитировании этой статьи сноска на dоі обязательна

\section{Право и политика $12(167) \cdot 2013$}

ности по вопросам связанным с коррупцией (правовой нигилизм), либо низкий моральный уровень населения, активность организованных преступных формирований в данной области, выработанное годами мнение о том, что коррупция это не есть зло, а норма поведения в обществе и т.п.

3. Политические.

Политика и коррупция, это явления тесно связанные.

Нормы, регулирующие общественные отношения, определяющие основы, устройство и функционирование государства и общества являются неотъемлемым жизненно важным элементом обеспечения национальной безопасности, в том числе антикоррупционной безопасности государства 6 .

Особенность государственного строя, это основа политической составляющей любого государства. Кажется, что государства, где властная компетенция рассредоточена между различными уровнями структур государственного аппарата (республиканская и демократические формы правления) по сути, должны быть менее подвержены коррупционному «заражению» нежели государство, где власть сосредоточена в руках небольшой группы лиц, которая может использовать ее по своему усмотрению, например при монархии.

В действительности, все наоборот. В настоящее время, в России органы государственной власти имеют такой громоздкий управленческий аппарат, что контролировать его с каждым днем становится все труднее и труднее. Его «раздутость», а также принцип «своих не сдаем» или «круговая порука» чиновников практически могут свести на нет всю антикоррупционную работу, проводимую в нашей стране.

Как считают эксперты чиновничий и судебный «беспредел» достигает иногда неимоверных масштабов. Отметим, что вряд ли власть пронизанная коррупцией снизу доверху будет бороться сама с собой․

Наличие возможности по своему усмотрению выбрать между различными вариантами поведения при разрешении конкретного вопроса, наряду с недоработками в законе и порождают коррупцию.

Как правило, данные возможности проявляются в следующем:

- увеличения срока рассмотрения вопроса;

\footnotetext{
${ }^{6}$ Андреев М.В. Конституционные и международные политикоправовые принципы обеспечения национальной безопасности [текст] / М.В. Андреев / Право и политика. - 2013. - № 6 (162) - c. $803-808$

${ }^{7}$ Илюхин В.И. О коррупции и ее причинах // Право и безопасность. 2008. № 4. С.68-72.
}

- возможность определения санкций налагаемых за конкретное правонарушение либо не наложение таковых в целом;

- необязательность совершения или не совершения определенного правопорождающего действия, как правило, препятствующего дальнейшему рассмотрению вопроса;

При рассмотрении вопроса в индивидуальном порядке гражданин может обеспечить благоприятное и быстрое для себя решение за «дополнительное вознаграждение».

Закрытость процедур совершаемых должностным лицом и как следствие, невозможность их проверки, то о чем постоянно говорится и с чем мы сталкиваемся - бюрократическая волокита, все это, а также много другое, вот политические причины и условия, способствующие укреплению коррупционной составляющей.

Также наряду с вышесказанным, в качестве политических причин способствующих коррупции можно выделить и процесс сращивания власти и бизнеса. Наряду с неразвитостью института легального лоббирования экономических интересов и неспособности общества контролировать власть, отсутствие чётко продуманной и последовательной антикоррупционной политики, в свою очередь является последствием полной неготовности политических партий к отказу от использования коррупции, как инструмента политической борьбы. Более того, следует отметить, что неразвитость института коллективной и индивидуальной политической ответственности за последствия коррупционного поведения высших чиновников порождает негативное отношение к этому со стороны населения.

Например, родственники не могут состоять на государственной службе, если один из них находится в служебной зависимости от другого ${ }^{8}$.

Можно отметить, что высокая степень общественно-политических свобод повышает вероятность огласки и, как результат, раскрытия коррупционных действий. Таким образом, свободное гражданское общество является залогом низкой коррумпированности государства, что вряд ли возможно в настоящее время. Также необходимо выделить то, что общая политическая нестабильность сама по себе провоцирует рост коррупции.

\section{4. Правовые.}

Основная правовая детерминанта, способствующая укреплению позиций коррупции, связана с неэффективной проработанностью и применением антикоррупционного законодательства.

\footnotetext{
${ }^{8}$ п.5 ч.1 Ф3 «О государственной гражданской службе в РФ» // Собрание законодательства Российской Федерации. 2004. № 31. Ст. 3215.
} 
DOI: 10.7256/1811-9018.2013.12.10278

При цитировании этой статьи сноска на dоі обязательна

Закон и правопорядок

При анализе правовых причин, особо следует обратить внимание на то, что органы законодательной власти зачастую сами являются объектами коррупционной направленности, а иногда и участниками, что в значительной степени тормозит борьбу с коррупцией.

Сами по себе правовые причины способствующие развитию коррупции находятся во взаимосвязи с правоприменением, законотворчеством и влияют на правосознание, правовое воспитание и поведение.

По своей сути в данной области наблюдается замкнутый круг, правовая норма по своей сути предусматривает некую свободу усмотрения при ее применении, чем больше эта свобода, тем больше можно говорить о свободе и демократии, но в свою очередь это же и порождает возможности для злоупотребления. Наличие пробелов в законе, неоднозначное толкование правовых норм, широкие возможности для применения норм права по своему усмотрению к различным субъектам это, а также много другое порождает и способствует развитию коррупции.

Проведенное исследование показало, что, несмотря на то, что основные причины, способствующие возникновению и росту коррупционной составляющей в нашей стране, находятся в области экономики, их нельзя и не нужно рассматривать в отрыве от остальных, поскольку все они находятся в непосредственной взаимосвязи между собой.

Невозможно изучить и выработать отдельные средства и методы борьбы по конкретному отдельно взятому направлению, будь то политическое, экономическое, социальное либо правовое. Поскольку сами по себе причины, выявленные в отдельно взятой области не могут оказать негативное влияние, не будучи связанными между собой: возможность повысить свой доход + отсутствие (либо низкий уровень) нравственного воспитания + отсутствие полного (либо крайне низкий) контроля со стороны государства + наличие правовых «лазек»= коррупция, вот один из примеров возможного поведения коррупционера.

Таким образом, для того что бы выработанные, на основе изучения причин и условий, средства и методы направленные на борьбу с коррупционной системой, дали наибольший положительный эффект, необходимо что бы они воздействовали в широком диапазоне и имели максимально возможный универсальный характер.

Такое возможно, когда правовые нормы, регулирующие действия должностных лиц исключат полную возможность при принятии решений не соответствующих предписаниям закона, при этом со стороны государства должен быть постоянный контроль за их работоспо- собностью, а случае необходимости внесений соответствующих изменений, при том, что общественность должна иметь свои средства наблюдения и воздействия в случае возникновения признаков характерных для коррупционера, при наличии условий препятствующих возникновению коррупционных мотиваций в личности (например, усиление ответственности или повышение уровня социальной защищенности).

И не смотря на все выше изложенное, до тех пор, пока будут те, кто в силу своих морально-нравственных качеств желает воспользоваться «коррупционными благами» и увеличить свое благосостояние, и тех, кто может и хочет этому поспособствовать, и до тех пор, пока данные факторы будут находить взаимные точки соприкосновения и не будет исключен хотя бы один из них, справиться с коррупцией будет практически невозможно.

\section{Библиография:}

1. Алексеев С.В., Мостовая И.В. Социальная обусловленность коррупции // Вестник ЮРГТУ (НПИ). 2013. № 1 C.181-188.

2. Гостева С.Р. Противодействие коррупции - важнейшее условие укрепления национальной безопасности России.// Юридический мир. 2011. № 1.

3. Голованов Е.И. Правовые средства борьбы с коррупцией в России XVI-XIXвв. (историко-правовое исследование): дис. ...канд. юрид. наук. - М., 2002.

4. Илюхин В.И. О коррупции и ее причинах // Право и безопасность. 2008. № 4. С.68-72.

5. Интернет-интервью с руководителем аппарата Комитета Государственной Думы по безопасности и противодействию коррупции Соловьевым И.Н. «О современном состоянии антикоррупционного законодательства» (29 января 2013 г.) // СПС «Гарант». Версия от 28.07.2013 г.

6. Лахман А.Г. Коррупция и противодействие коррупции: проблемы правопонимания // Власть и управление на Востоке России. 2013. № 1. С. 129-134

7. Послание Президента РФ Д.А. Медведева Федеральному Собранию РФ от 5 ноября 2008 г. // Российская газета. 2008. № 23.

8. Куракин А.В., Костенников М.В. Административноправовое противодействие коррупции в системе государственной службы и в деятельности сотрудников полиции Российской Федерации и зарубежных государств // NB: Российское полицейское право.2013.-1.-C. 65-83. URL: http://www.e-notabene.ru/pm/ article_735.html 


\section{Право и политика $12(167) \cdot 2013$}

9. Бут С.С. Система административно-правовых средств противодействия коррупции в таможенных органах Российской Федерации // NB: Административное право и практика администрирования.-2013.-9.-C. 88-98. URL: http://www.enotabene.ru/al/article_10137.html

10. Кабанов П.А. Президиум Совета при Президенте Российской Федерации и образуемые им рабочие органы как высшие федеральные специализированные антикоррупционные учреждения: вопросы повышения качества правового регулирования и эффективности их деятельности // NB: Административное право и практика администрирования.-2013.-2.-C. 91-104. URL: http:// www.e-notabene.ru/al/article_370.html

11. Астанин В.В. Противодействие коррупции и возмещение ущерба от нее // NB: Административное право и практика администрирования. - 2013. - 7. - C. 88-99. URL: http://www.e-notabene.ru/al/ article_9924.html

12. Бакрадзе А.А. Уголовно-правовой анализ проекта постановления Пленума Верховного Суда РФ «О судебной практике по делам о взяточничестве, коммерческом подкупе и иных коррупционных преступлениях» // NB: Вопросы права и политики. -2013. - 5. - C. 165-180. URL: http://www.e-notabene. $\mathrm{ru} / \mathrm{lr} /$ article $793 . \mathrm{html}$

13. Куракин А.В. Административно-правовые аспекты юридической ответственности в механизме противодействия коррупции в системе государственной службы Российской Федерации // NB: Административное право и практика администрирования.-2013.-7.-C. 137-157. URL: http://www.e-notabene.ru/al/article_9954.html

14. Андреев М.В. Конституционные и международные политико-правовые принципы обеспечения национальной безопасности [текст] / М.В. Андреев / Право и политика.-2013.-№ 6 (162)-с. 803-80

\section{References (transliteration):}

1. Alekseev S.V., Mostovaya I.V. Sotsial'naya obuslovlennost' korruptsii // Vestnik YuRGTU (NPI). 2013. № 1 S.181-188.

2. Gosteva S.R. Protivodeistvie korruptsii - vazhneishee uslovie ukrepleniya natsional'noi bezopasnosti Rossii.// Yuridicheskii mir. 2011. № 1.
3. Golovanov E.I. Pravovye sredstva bor'by s korruptsiei v Rossii XVI-XIXvv. (istoriko-pravovoe issledovanie): dis. ...kand. yurid. nauk. - M., 2002.

4. Ilyukhin V.I. O korruptsii i ee prichinakh // Pravo i bezopasnost'. 2008. № 4. S.68-72.

5. Lakhman A.G. Korruptsiya i protivodeistvie korruptsii: problemy pravoponimaniya // Vlast' i upravlenie na Vostoke Rossii. 2013. № 1. S. 129-134

6. Kurakin A.V., Kostennikov M.V. Administrativnopravovoe protivodeistvie korruptsii v sisteme gosudarstvennoi sluzhby i v deyatel'nosti sotrudnikov politsii Rossiiskoi Federatsii i zarubezhnykh gosudarstv // NB: Rossiiskoe politseiskoe pravo. - 2013. - 1. - C. 65-83. URL: http://www.e-notabene.ru/pm/article_735.html

7. But S.S. Sistema administrativno-pravovykh sredstv protivodeistviya korruptsii $v$ tamozhennykh organakh Rossiiskoi Federatsii // NB: Administrativnoe pravo i praktika administrirovaniya. - 2013. - 9. - C. 88-98. URL: http://www.e-notabene.ru/al/article_10137.html

8. Kabanov P.A. Prezidium Soveta pri Prezidente Rossiiskoi Federatsii i obrazuemye im rabochie organy kak vysshie federal'nye spetsializirovannye antikorruptsionnye uchrezhdeniya: voprosy povysheniya kachestva pravovogo regulirovaniya i effektivnosti ikh deyatel'nosti // NB: Administrativnoe pravo i praktika administrirovaniya.-2013.-2.-C. 91-104. URL: http:// www.e-notabene.ru/al/article_370.html

9. Astanin V.V. Protivodeistvie korruptsii i vozmeshchenie ushcherba ot nee // NB: Administrativnoe pravo i praktika administrirovaniya.-2013.-7.-C. 88-99. URL: http://www.e-notabene.ru/al/article_9924.html

10. Bakradze A.A. Ugolovno-pravovoi analiz proekta postanovleniya Plenuma Verkhovnogo Suda RF «O sudebnoi praktike po delam o vzyatochnichestve, kommercheskom podkupe i inykh korruptsionnykh prestupleniyakh» // NB: Voprosy prava i politiki. 2013. - 5. - C. 165-180. URL: http://www.e-notabene. $\mathrm{ru} / \mathrm{lr} /$ article_793.html

11. Kurakin A.V. Administrativno-pravovye aspekty yuridicheskoi otvetstvennosti v mekhanizme protivodeistviya korruptsii $\mathrm{v}$ sisteme gosudarstvennoi sluzhby Rossiiskoi Federatsii // NB: Administrativnoe pravo i praktika administrirovaniya. - 2013. - 7. - C. 137-157. URL: http://www.e-notabene.ru/al/article_9954.html

12. Andreev M.V. Konstitutsionnye i mezhdunarodnye politiko-pravovye printsipy obespecheniya natsional'noi bezopasnosti [tekst] / M.V. Andreev / Pravo i politika. - 2013. - № 6 (162) - s. 803-80 